\title{
ARTICLES
}

\section{On Being Morally Expendable}

Inevitably, assessing the moral value of life seems to leave us stuck between a rock and a hard place. If we hold that life is intrinsically valuable, that commits us to respecting plants and paramecia as ends in themselves and to explaining how the change from organic to inorganic is in and of itself a moral loss. That evaluation seems exaggerated, and who knows how even to begin to explain the intrinsic moral superiority of the organic to the inorganic! On the other hand, if life is valuable only as a necessary condition for other, morally significant goods, such as happiness or conscientious action, it follows that the taking of life is morally significant only where it affects the amount of or opportunities for these goods. This conclusion is objectionable because it seems to leave the individual's life morally insignificant and unprotected: as long as he will be replaced by an (at least) equally happy or conscientious individual when he is killed, it would seem to be morally indifferent whether he is allowed to continue his life or whether he is killed and replaced.

Since I agree that the rock is a rock--that is, I know of no reason to believe that the organic is in and of itself morally more valuable than the inorganic--the point of this paper will be to show that the hard place is softer than it looks. To do this I want, first, briefly to indicate how limited the practical consequences of the replaceability argument are. ${ }^{1}$ Then, on the theoretical side, I want to show that the replaceability argument does not work from all standard, general moral viewpoints and that an argument recently put forward by Peter Singer, among others, to the effect that utilitarians must accept the replaceability argument is fallacious. Thus, the point of this paper is not to prove that the replaceability argument commits some logical blunder, for it does not; rather, the main point of this paper is that the replaceability argument requires certain presumptions concerning moral worth, that not all credible, general moral viewpoints make the required assumptions, and that there are even credible forms of utilitarianism which do not make the required assumptions. Consequently, even if we agree that life is morally valuable only as a necessary condition for other goods, we are not stuck with the replaceability argument.

First of all, even those of us who work in the clouds should be aware that just about the only current, routine killing of animals which the replaceability argument would even be relevant to justifying is that involved in the taking of some animals bred, raised, and more or less released to be game animals. The replaceability argument cannot be used to justify the killing of wild animals, because by and large (i) they would have existed whether or not we had an interest in killing them, (ii) we do not do anything to replace the ones we kill, and (iii) it is not necessary that the wild animals we kill die in order that the ones which replace them might live. Nor can the replaceability argument be used to justify the killing of most domesticated animals or animals bred and raised in captivity, e.g., for laboratory use. This is because most of these animals do not lead a life worth living. Even when not in pain, most animals raised for slaughter or bred for laboratory use lead frustrated, boring lives which fall far short of 
the quality of life which gives being alive its moral value. Consequently, although the replaceability argument provides an intriguing puzzle for moral pinilosophers to ponder, it is of little to no consequence as a justification for our current treatment of animals.

Turning to the puzzle, its solution depends on two things: what is the good that gives moral value to life, and what is the relation of individuality to that good? ${ }^{2}$ Rather than try to resolve long-standing moral disputes in order to answer the first of these questions, I propose simply to lay out six more or less standard answers to that question. I shall then consider how important or unimportant individuality is from each of these six moral viewpoints.

The first two of these viewpoints concern autonomy and the belief that autonomy merits our respect. Kant argued that autonomous individuals should be treated as ends in themselves because autonomy is a necessary condition for the possibility of morality. ${ }^{3}$ The idea here is that since morality is intrinsically good, the source of morality should be respected as an intrinsic good. So, as long as an individual capable of right and wrong is innocent of crime, he has earned our unqualified respect.

The second autonomy-based moral viewpoint 1 wish to consider is of more recent vintage and is summarized in the popular slogan "we don't have a right to force our values onto others." The idea here is that if an individual is capable of valuing things for himself, then he should be allowed to do so and to pursue his own values (as long as doing so is not unfairly injurious to other independent valuers). This idea of autonomy, i.e., being an independent source of evaluations, differs from the Kantian conception of autonomy as the ability to recognize moral values.

That independent valuers should be respected has been a fundamental presumption of many natural rights and egoistic moral philosophies, and it has become particularly important in recent work in medical ethics, where it underlies many arguments for patients' rights. This moral outlook was also adopted by Tom Regan in a recent argument concerning animal rights:

The suggestion before us, then, is that all but the irreversibly comatose have inherent value because all these humans have a life which is of more or less positive or negative value for them, and this logically independently of whether they (the humans in question) are valued by anyone else. Here, therefore, we have a way of illuminating why it would be wrong to treat these humans merely as a means. This would be wrong because it would fail to acknowledge and respect the fact that they are the subjects of a life whose value is logically independent of any other being's taking an interest in it. Thus, in treating these humans merely as means one treats them as if their value was logically dependent on their answering to the needs, purposes, etc., of others, when in fact, they, as the subjects of a more or less good life, have value that is logically independent of their being valued as a means by anyone else. ${ }^{4}$

I have yet to see a convincing defense of the idea that because an individual is capable of making his own evaluations we ought to permit him to do so--although some defense in terms of the "do only that which you can will as a universal law" form of the 
categorical imperative seems possiblebut its wide acceptance in current moral philosophy, both professional and popular, seems beyond question. ${ }^{5}$

1. shall label the first of these autonomy-based moral outlooks "the Kantian-autonomy view" and the second variety "the independent-valuer view".

The remaining four moral outlooks on what gives life value are all forms of utilitarianism. I propose, following Peter Singer here, to divide utilitarianism into classical vs. preference theories and total view vs. prior existence theories. ${ }^{6}$ Classical utilitarianism commands us to do that which will maximize happiness, while preference utilitarianism commands us to do that which will accord, as far as possible, with the preferences of those to be affected by our action. These two forms of utilitarianism are different because individuals may not (e.g., due to ignorance) prefer that which would maximize happiness and because one may prefer something (e.g., life) the loss of which would not occasion unpleasant feelings. The total view form of utilitarianism commands us to maximize the amount of utilitarian good in the world, while the prior existence view commands us to maximize that good for the beings already in the world. The difference between these two forms of utilitarianism is that the former, but not the latter, requires direct concern for the preferences or happiness of unborn individuals or generations. On the prior existence view, the future interests of the unborn may have to be taken into account, but only insofar as the prospect of their fulfillment or frustration affects the preferences or happiness of currently existing individuals.

Combining these two distinctions yields four versions of utilitarianism: the preference-total view, the preference-prior existence view, the classical-prior existence view, and the classical-total view.

Now, how does individuality fare when measured by these six different ways of establishing moral value? From the Kantian-autonomy perspective, the only forms of life which merit our moral respect are those which are capable of moral action, and individuals with this capacity merit our respect so long as they are innocent of crime. The Kantian imperative to treat no man as a means merely is not a command to maximize the number of conscientious agents in the world; rather, it asserts that those with the capacity for recognizing and doing right and wrong (and who are innocent of wrong) thereby merit our respect. In the case of individuals who have had the opportunity to do wrong but have not done so--which is the paradigm case here--this expression of good moral character may be said to have "earned" these individuals our respect. Just as a hard worker has earned his wage, so someone of good moral character has earned the right to be happy, and in this world, at least, others must respect the moral individual's desires, wants, needs, etc., and his attempts to fulfill them, if he is to achieve the happiness to which he is entitled. Among these needs (as far as we know), is the need to be alive in order to experience happiness. So, although killing one individal of good moral character (or with the capacity for it) and replacing him with another (e.g., slaying one normal human infant and replacing it with another) would not reduce the amount of (capacity for) good moral character in the world, it would deprive the slain individual of what he is due on the basis of his (capacity for) good moral character. Thus, the Kantian-autonomy view protects the individual against the replaceability argument because it commands us to respect the right to happiness of those with the 
capacity to recognize and act on moral values, while slaying such an individual would (for all we know) deprive him of that to which he is entitled.

It may be thought that all this is irrelevant to the matter at hand, the moral permissibility of killing and replacing non-human animals, since Kant held that only those who can act from a sense of duty can have good moral character, that only rational beings can act from a sense of duty, and that only humans are rational animals. While this is true of Immanuel Kant, it need not be true of the Kantian-autonomy position. Some philosophers, such as David Hume, have argued that some non-human animals are rational, and others, such as Richard Watson, have argued that some non-human animals are capable of acting out of a sense of duty ${ }^{7}$. Furthermore, one can combine the view that individuals of good moral character have earned our respect with non-Kantian theories of good moral character, e.g., Hume's idea of virtue arising from a strong sense of sympathy. I believe most people, philosophers included, would reject Kant's claim that acting from a sense of duty is the only morally estimable motive. Most of us credit generous sentiments as a morally worthy motive. However, acknowledging the moral significance of sympathy and other generous sentiments opens the door wide to arguing that many non-human animals who intentionally and sincerely do morally good deeds, or who are at least innocent of crime, have earned our respect for their lives on Kantian-autonomy grounds. ${ }^{8}$ Consequently, these animals could not be killed and replaced, according to the Kantianautonomy view.

Turning to the independent valuer view, it holds that we should respect all individuals capable of forming their own values. There are two points that need to be clarified in order to discuss this position: what counts as making one's own values, and, correlatively, how are we to tell if others are (capable of) doing this? Some philosophers, such as Ruth Cigman in her recent article, "Death, Misfortune, and Species Inequality," make of valuing a fairly abstract, intentional, conceptual process of which preference behavior does not provide significant evidence:

To be a possible subject of misfortunes which are not merely unpleasant experiences, one must be able to desire and value certain things. The kind of misfortune which is in question here is death, and to discover whether this is a misfortune for an animal, we must ask whether, or in what sense, animals don't want to die. Of course, in some sense this is true of virtually all animals, which manifest acute fear when their lives are threatened. Yet blindly clinging on to life is not the same as wanting to live because one values life. This is the kind of desire for life of which persons are capable. It is this which gives sense to the claim that death is a misfortune, even a tragedy, for a person."

For philosophers like Cigman, linguistic ability is necessary both for being able to make one's own evaluations and for communicating to others that one has this capacity.

This position has the virtue of avoiding the opposite extreme of saying that plants which turn their leaves to follow the sun are making their own evaluations and showing this to us. However, it seems arbitrary to cut off valuing at some fairly intellectual level. Infants, children, and many animals seem obviously capable of being happy or unhappy and to prefer, want, desire, grab for, pursue, or "value" those things which 
bring them the former. Also, we can usually tell what infants, children, and animals want without being told; we need only to watch their course of action. Thus, our everyday dealings with infants, children, and animals suggest that being a sentient agent, rather than having linguistic ability, is what is necessary for being (and for being recognized as being) an independent evaluator. The burden of proof is on those who would deny this conclusion--and that burden cannot be met by a stipulative definition.

It follows from the independent evaluator viewpoint that we should (other things being equal) respect the values and pursuits of all sentient agents. Since they cannot pursue their values unless they are alive and since another, replacement individual would pursue his own values, rather than those of the individual he replaces, it also follows that the independent evaluator view protects many animals against the replaceability argument. Let me emphasize that the individual need not directly value life itself (whatever that may mean) in order to have his life protected by the independent evaluator view. What individual $X$ values is not, for example, just lying in the sun. What he values is his lying in the sun--this may be clearly evidenced by his chasing away other individuals already lying in the sun, so that he may take their place. Individual $Y$, brought in to replace the slain $X$, will not, of course, value $X$ 's lying in the sun; he will value his own ( $Y^{\prime} s$ ) lying in the sun. So, replacing $X$ with $Y$ will not provide an adequate foundation for the continued pursuit of what $X$ valued, even where $X$ did not directly value his own life. Consequently, for a sentient agent's values and pursuits to be respected, his life must be respected, whether or not he ever contemplates that life and values it directly.
Thus, both autonomy-based moral viewpoints deny that it is morally permissible (in many cases) to kill an animal and replace it with a similar animal. Either such killing and replacing would deny the animal of good moral character the respect it has earned, or it would deny the sentient agent the respect due the pursuit of his independent values.

Turning to the utilitarian options, the preference-total view option maintains that we should do that which will accord (as far as possible) with the preferences of those currently alive and the likely preferences of future individuals and generations. Here, once again, we must deal with the psychological and epistemological issues of what counts as having a preference (or being capable of having preferences) and how we are to know when others have preferences (or are capable of having preferences).

As valuing has sometimes been made out to be an intellectual activity, so preferring is sometimes made out to be an activity requiring self-contemplation and the projection and analysis of future alternatives. For example, Peter Singer writes:

A being which cannot see itself as an entity with a future cannot have a preference about its own future existence. This is not to deny that such a being might struggle against a situation in which its life is in danger, as a fish struggles to get free of the barbed hook in its mouth; but this indicates no more than a preference for the cessation of a state of affairs that is perceived as painful or threatening. Struggle against danger and pain does not suggest that the fish is capable of preferring its own future existence to nonexistence. ${ }^{10}$ 
Immediately, one may wonder how a being that cannot see itself as a being with a future could possibly perceive a state of affairs to be "threatening" or could possibly struggle against "danger". Singer's attempt both to acknowledge obvious value expressing behaviors of animals yet to deny that they have preferences seems to be self-contradictory.

Furthermore, desiring seems to be a paradigm of preferring, ${ }^{11}$ yet desiring requires neither reflective selfconsciousness nor great intellectual ability. ${ }^{12}$ Furthermore, it would be reasonable to expect that all sentient beings, no matter how limited their self-consciousness, intellect, and sense of time, would have preferences. There would be no evolutionary point to their being sentient if they could not recognize, desire, and pursue those things which give them pleasure and recognize, desire to avoid, and seek to avoid those things which give them pain.

When it is maintained that few, if any, animals can have preferences, because they cannot see themselves as entities with a future, it is presumed that self-consciousness and having a sense of the future are confined to self-contemplation and to having a sense of the indefinite expanse of time awaiting us. However, in addition to self-contemplation, there is the sensory self-consciousness involved in feeling pleasure and pain and the practical consciousness of oneself as an agent in the world, having a "lived body" of powers at his command, needs to be met, and vulnerabilities to be protected. ${ }^{23}$ Being an agent also requires having a sense of the future--which, let us not forget, though it may extend indefinitely, begins immediately. This is because agency requires recognizing that one thing will lead to another, e.g., that if one goes to the back of the house and pushes on the pet door, then he will be able to get out of the house. Self-conscious/non-self-conscious and aware of the future/unaware of the future are not in the same set with pregnant/not pregnant; there are various forms and degrees of selfconsciousness and awareness of the future, and these varieties give rise to varying capabilities for having preferences.

Again, when it is denied that animals can have a preference for life, it is presumed that to prefer life requires contemplating an indefinite future existence. But why should "preferring" $X$ require that we contemplate $X$ when the question of $X$ is not raised by the environment? Cannot one "prefer" $X$ and show others that he prefers $X$ if, whenever his environment raises the issue of $X$, he pursues $X$ (other things being equal)? It does not seem to do harm to the logic of "preferring" to say that an animal who acts to preserve his life when it is threatened prefers to remain alive and is amply demonstrating his preference. Many animals even seem to experience and deal with the conflict of desires which some philosophers might want to insist is essential to the logic of "preferring"; e.g., when faced with danger to their young or group, many animals seem both to want to flee and to feel they must stay and defend their young or group. Perhaps humans are the only animals who are morbid enough to contemplate life and death when that issue is not forced upon them, but preferring life to death does not require such morbid fascination. Just as was the case with self-consciousness and a sense of the future, preferring comes in a variety of forms and degrees, and it is arbitrary to consider only the intellectual extreme of that variety when making moral judgments.

When trying to figure out what will best accord with the preferences of 
those who will likely be affected by our action, we must recognize that many animals are, like children, desiring, sentient agents, even if they are not self-contemplative beings. Their behavior can make their desires known to us, and among these desires will ordinarily be a desire not to be killed. Also, even if the animal is not aware that his long term existence is required to fulfill some of his desires, e.g., the raising of his young, his remaining alive for a long period of time may be necessary for fulfilling those preferences; consequentiy, doing what accords with those preferences requires respecting the animal's life. Furthermore, among the animal's current desires will ordinarily be a number which are essentially self-centered, e.g., his continuing to lie in the sun, which will remain frustrated even if the animal were replaced by another animal with similar preferences. Thus, the killing of a non-self-contemplative animal and replacing it with another is a morally significant act from the preference-total view utilitarian viewpoint.

Whether such killing and replacing is morally permissible remains undecided, however, and that is true whether we are dealing with animals or with humans. The self-contemplative individual does have an advantage, for he may prefer not to worry about his being slain and replaced while his demise is still a long way off, whereas the non-self-contemplative individual can have no such worry; he can only prefer not to be killed, and that only when the time of slaughter is close at hand. However, if the possibility of long-range foreknowledge of slaughter could be eliminated, merely a technological problem which some science fiction writers have already resolved, then the permissibility of slaughter and replacement would be the same for both humans and animals on preference-total view utilitarian grounds. ${ }^{14}$
Whether or not long-range foreknowledge is involved, the direct. moral significance of killing humans or animals is that it will frustrate some of their preferences. However, if the slain are replaced, their demise will also permit the fulfillment of the preferences of the replacement individuals (which would, by hypothesis, not be possible without the slaughter of the others). It follows (neglecting indirect issues) that if individuals were slaughtered when half the preferences that could be fulfilled in their lives have been fulfilled and were replaced with individuals having similar life expectancies, that would accord with the preferences of the born and the unborn just as well as allowing the original individuals to live out the second half of their lives. ${ }^{15}$ Also, if the number of an individual's preferences that could be satisfied in a year was the same throughout his life, then slaughter and replacement at any time in his life would be permissible, and if the number of possible fulfillments were higher in earlier years than in later years, it would even be preferable to slaughter an older individual and replace him with a younger one, rather than allowing the old individual to live out his life. Thus, if we could compute the rate of fulfillment of preferences, preference-total view utilitarianism could sanction the slaughter and replacement of animals and humans.

Moving on, we may deal with both the preference-prior existence and the classical-prior existence forms of utilitarianism at one stroke. Both of these views limit direct moral concern to currently existing individuals, the former to according with their preferences, the latter to maximizing their happiness. This clearly rules out the replaceability argument. That argument presumes that the future preferences or happiness of the unborn can be used as a substitute for the losses suffered by the slain; however, 
insisting that our direct moral obligations are limited to currently existing individuals denies direct moral significance to the future preferences and happiness of the unborn and, thereby, denies that the latter can be morally equated with the former. So, any prior existence moral outlook will protect the individual against the replaceability argument.

Turning to classical-total view utilitarianism, it requires us to do that which will maximize the amount of happiness in the world. From this viewpoint, killing, even painlessly, is a morally significant act, for it eliminates the possibility of the future happiness of the slain (assuming that the future held happiness for the slain individual and that death does not lead to a happier form of existence than continuing life would have): However, if another individual with similar prospects for the future is substituted for the slain individual (and would be brought into existence only if the other were slain), then the balance of happiness in the world is unaffected. Consequently, classicaltotal view utilitarianism provides moral significance for life but does not provide any protection for the individual against the replaceability argument. The individual is merely a receptacle for happiness; so, as long as there is a ready supply of receptacles to replace the broken ones, nothing important will be lost through the breakage.

Once again, this conclusion applies to humans as well as to animals. If humans are not distressed by foreknowledge of their impending slaughter and replaclement (because the practice is hidden from them) or if they have already enjoyed half the happiness their lives could provide or if happiness in later years is sufficiently less than in earlier years to counterbalance the depression caused by knowing that one is to be slain and replaced by a youngster, then classical-total view utilitarianism could not only permit but even require the - slaughter and replacement of humans. Since humans have greater ability to foresee their slaughter and replacement than do animals, there would be greater technological problems in applying the replaceability argument to humans than to animals. However, humans' extensive foresight provides no more fundamental an obstacle to slaughter and replacement on classical-total view utilitarian grounds than does the limited foresight of animals. The only differences here are the details of implementation.

Once it has been argued, as it was above, that animals have preferences, it can be seen that the difference between preference and classical forms of utilitarianism is not important where the question is the permissibility of slaughter and replacement. Whether one is dealing with humans or animals and with happiness or preferences, the crucial issue is whether a total view or a prior existence view will be adopted. This conclusion naturally leads to the question, if we are going to be utilitarians, is there some reason which impels us to be total view rather than prior existence utilitarians? That total view utilitarianism could, while prior existence utilitarianism could not, sanction the slaughter and replacement of humans would, in the eyes of most people, philosophers included, put the burden of proof on the shoulders of the total view. Also, as Peter Singer points out, total view utilitarianism has the counterintuitive consequence that it requires us to bring as many happy individuals into the world as possible. It follows that a couple whose happiness (or preferences) would be compromised by a smaller amount than the happiness (or fulfilled preferences) awaiting a child they could have would be under a moral obligation to have that child. ${ }^{16}$ Prior existence 
utilitarianism leads to no such consequence.

However, Peter Singer also argues that prior existence utilitarianism leads to another, equally counterintuitive conclusion:

How do we square prior existence utilitarianism with our intuitions about the case when a couple are considering having a child who, perhaps because it will inherit a genetic defect, would lead a thoroughly miserable life and die before its second birthday? We would think it wrong for a couple knowingly to conceive such a child. ${ }^{17}$

Singer goes on to provide the following resolution for this problem but also indicates that he finds this answer insufficient:

Perhaps the best one can say--and it is not very good-is that there is nothing directly wrong in conceiving a child who will be miserable, but once such a child exists, since its life can contain nothing but misery, we would reduce the amount of pain in the world by an act of euthanasia. But euthanasia is a more harrowing process for the parents and others involved than non-conception. Hence we have an indirect reason for not conceiving a child bound to have a miserable existence. ${ }^{18}$

I would agree that this indirectwrong answer does not provide an adequate response to the problem Singer has raised for prior existence utilitarianism. However, I think the following can be added to provide an adequate response to this problem. Regarding the matter of our intuitions concerning this case, I am not sure we have any, for this is an utterly fantastic case. Cases somewhat like it do occur, but they are cases where there is a statistically significant chance that a couple's infant will inherit a debilitating disease or defect and, of course, a statistically significant chance that it will not. In these cases 1 do not find there is a well-established intuition that it would be wrong for couples to consider conceiving children, especially if they were prepared to abort a fetus discovered to have inherited the debilitating disease or defect. Similarly, we encounter cases of people whose children will likely (or even almost certainly) inherit their defects, e.g., retardation or blindness, and will, consequently, be condemned to leading a life we would not find satisfying. However, those people may find that life satisfying and, consequently, feel they are not bringing misery into the world by having children. Again, it is not intuitively obvious they are wrong.

In contrast to such real cases, Singer's case verges on being inconceivable. Somehow, the couple must know with virtual certainty that their prospective child will inherit a disease which will make its life undeniably miserable and kill it before the age of two. Furthermore, this couple must be so desperate to conceive their own child, that they would rather bring this monstrosity into the world and care for it $^{19}$ than adopt a child. I doubt that such people and such a case exist, and 1 do not think that the acceptability of moral principles hinges on their ability or inability to handle such unheard of cases.

But if such people did exist, they would have a perverted idea of reproducing and parenting and would show, by keeping the child alive for its two miserable years, their willingness to use others merely as means to their own happiness. Consequently, this whole project of parenting would express a kind of demented character which would give the project a strong 
immoral value. I think this bad-character evaluation accounts for one idea that, I presume, Singer intended to suggest with this case, viz., that there would be something demented, perverse, selfish, or morally insensitive involved in bringing a miserable child into the world or even in just seriously contemplating doing so. Prior existence utilitarianism can account for this intuition, since this is an evaluation of character, and prior existence utilitarianism no more precludes making character evaluations than does total view utilitarianism.

In discussing bringing a miserable child into the world, it is easy to lump together three stages of the process which are importantly different in their moral value: child,

(i) intending to conceive such a

(ii) conceiving such a child, and

(iii) keeping such a child alive.

As just discussed, (i) is a bizarre project and expresses bad moral character, if the prospective parents intend to keep the child alive. If, however, they intend to abort the potentially miserable child before it develops sufficiently to suffer, then their intention is to satisfy their bizarre compulsion to conceive in a way which does no direct harm from any utilitarian viewpoint. Far from being wrong, such a project would be morally praiseworthy, for it (a) shows tolerance for unusual psychological needs, (b) expresses, in its willingness to sacrifice the pre-sentient fetus, a commitment to the idea that it is not species membership but the capacity to feel pleasure and pain (or to have preferences) which makes a being morally significant in itself, and (c) reponsibly projects a course of action which will satisfy the bizarre needs of the couple without causing harm to or frustrating the preferences of anyone else. Thus, on utilitarian grounds, "considering having a miserable child" is not obviously wrong, and prior existence utilitarianism can acommodate the character evaluations which are involved in morally evaluating (i).

Turning to (ii), if we set aside the pleasure involved and issues such as rape, it is morally neutral. There is nothing directly either morally right or morally wrong with conceiving a child which, if it is allowed to develop, will lead a thoroughly miserable life. Conceiving such a child could be wrong for the indirect reasons singer notes, i.e., aborting the pre-sentient fetus could be more disturbing for the couple (and others, too, perhaps) than not conceiving at all, but conceiving such a child could also be morally justifiable if the suffering associated with abortion were less than the frustration of not conceiving or if, as suggested above, the production of such a fetus were necessary for medical progress. Additionally, conceiving a potentially miserable child is like the moderate use of alcohol or other potentially debilitating drugs: by itself it is either morally innocuous or morally positive, due to the immediate satisfaction it provides; it becomes morally objectionable only if it is allowed to lead to consequences whose disvalue outweighs that immediate satisfaction. As long as one takes steps to insure that these adverse consequences will not occur, there is nothing directly wrong with such indulgences in the potentially harmful.

Finally, allowing a thoroughly and incurably miserable child to continue to suffer seems clearly immoral. Only the possibility of thereby making a great contribution to easing the suffering of others would justify keeping such a child alive. Satisfying the compulsion of the parents to have a living product of their own loins pales by comparison with the misery of such an infant. However, prior existence utilitarianism has no problem 
accounting for this evaluation of (iii), for at this stage the suffering child is an existing, sentient being. So, at the stage where we intuitively feel that a wrong is being done to the suffering child, prior existence utilitarianims also finds that, ceteris paribus, having, i.e., keeping, such a child is wrong.

Considering having a child who will be miserable if it is allowed to live and even conceiving such a child do not bring misery into the world. Misery is brought into the world only when that child has developed to the point where it can suffer and when it is allowed to continue to live and suffer. I think Singer believes his case poses a problem for prior existence utilitarianism because he does not clearly distinguish intention, conception, and maintenance and, consequentiy, transfers the intuitively negative moral evaluation of the third of these stages back to the earlier two stages. However, once we clearly distinguish these three stages, we can see that this case does not pose a problem for prior existence utilitarianism, since "bringing a miserable life into the world" refers to actualizing (or allowing to start operating) the capacity to suffer of an already existing individual. The difference between bringing a miserable life into the world and bringing misery into a life seems to be limited to the fact that in the latter case the individual's capacity to feel pleasure and pain (or to have fulfilled or frustrated preferences) has already been operating for a while, while in the former case we are considering its initial actualization. Since in either case the individual already exists, this difference does not constitute a difficulty for prior existence utilitarianism.

Finally, Singer maintains that to be satisfactory, prior existence utilitarianism would have to explain the following asymmetry: if the pleasure a possible child will have is not a reason for bringing it into the world, why is the pain a possible child will experience a reason against bringing it into the world? The prior existence view must explain the asymmetry between cases of possible children who are likely to have pleasant lives, and possible children who are likely to have miserable lives. 20

However, there is no need for such an explanation, for there is no asymmetry here. The possible happy life of a normal child and the possible miserable life of a deformed child become reasons for having, i.e., keeping, the normal child and not having, i.e., aborting, the deformed child only when the child is already in existence and its capacity for happiness or misery is ready to be actualized. At that stage the obligation to keep the normal child is as strong (on either classical or preference utilitarian grounds) as the obligation to abort the deformed child. Similarly, seriously considering conceiving and maintaining an assuredly miserable child is ordinarily an expression of bad moral character, while seriously considering conceiving and maintaining a normal child is ordinarily an expression of good, i.e., responsible, generous, or loving, character. ${ }^{21}$ The actual conceiving of either child is, of course, in itself just pleasant (ceteris paribus). So, at each stage there is symmetry in our evaluations concerning parenting a normal child and parenting a miserable one. I would guess that singer believes there is an asymmetry here because he is comparing our obligation (given current liberal intuitions) to abort an already existing, though not yet sentient, seriously deformed child with our lack of obligation (again, given current liberal intuitions) to conceive normal children. But once again, if we clearly distinguish intention, 
conception, and maintenance, the supposed obstacle to accepting prior existence utilitarianism disappears.

To sum up this discussion of Singer's objection to prior existence utilitarianism, first, that objection is based on a fantastic possibility, and it is at least not obvious that the fate of moral theories hinges on their ability or inability to handle the fantastic. Second, what would be demented or perverse in the project of parenting Singer describes is the character of the prospective parents, and prior existence utilitarianism has no more difficulty making character evaluations than does total view utilitarianism. Third, if we clearly distinguish the three stages of the project--considering having a miserable child, conceiving such a child, and keeping the child--it becomes clear that there is a definite, direct, moral wrong only at the third stage, but since the child already exists at that stage, prior existence utilitarianism has no difficulty accounting for that wrong. Finally, prior existence utilitarianism does not require any asymmetry in the criteria employed in determining our obligations concerning having or not having normal or miserable children. Thus, Singer's challenge to prior existence utilitarianism has been met. (And the strategy employed here does not suggest that a similar response to his challenge to total view utilitarianism could be made-here there is an asymmetry.)

There is one other objection to prior existence utilitarianism which might be raised, namely, that it would rule out obligations to future generations. One could, of course, have obligations to respect how currently existing people (and animals?) feel about the life prospects of future generations, but since they do not exist, we could not have direct obligations to them. This might seem a serious problem, for the idea of our obligations to future generations seems to be a fairly common one and has achieved some currency in environmental ethics. Nonetheless, I think the prior existence view is correct: we do not have obligations to future generations. And recognizing this need not pose an obstacle for the development of an effective environmental ethics.

On any given day, our obligation to do that which will maximize the long-range happiness or accord with the long-range preferences of those currently alive commits us to looking seventy-five to one hundred years into the future. ${ }^{22}$ I doubt that we are capable of making significant projections of use patterns, preferences, technological developments, and other important matters concerning the quality of life more than seventy-five to one hundred years into the future. So, if we insure that our environmentally significant practices will not lead us (humans and animals) to be dissatisfied with the quality of life available to us seventy-five to one hundred years hence, I think we will be doing the best we can. Also, let us not forget that every time a decision must be made about maintaining, altering, or abandoning a program, that decision would have to be based on a consideration of what would be best for the seventy-five to one hundred years stretching into the future from that date. Consequently, foregoing the idea of direct obligations to future generations would not cripple environmental ethics.

To summarize, four of the six moral theories considered here extend moral value to life in a way which protects individual humans and animals from the replaceability argument. The only moral theories considered here which provide no such protection are the two forms of total view utilitarianism. However, total view utilitarianism would sanction the replaceability 
of humans, as well as of animals, and would obligate us to have as many children and to breed as many animals as the earth can support without diminishing the over-all happiness (or fulfillment) in the world. The other four moral theories considered here do not encounter these difficulties. So, if these other theories do not fall prey to other, more serious difficulties--and we have seen that some proposed objections to prior existence utilitarianism fail--there would seem to be ample, animal-independent reason for even utilitarians to reject total view utilitarianism, thereby undercutting the replaceability argument. Therefore, from a theoretical, as well as a practical, perspective, the replaceability argument does not pose a serious obstacle to the development of animal rights and other attempts to improve the moral status and the lives of animals.

\section{Steve F. Sapontzis}

California State University, Hayward

Notes

1. By "the replaceability argument," I understand the formulation of it found in the March, 1982, issue of Ethics \& Animals $(111 / 1$, p. 1$)$ :

It is permissible, ceteris paribus, to use an animal and to kill it (for food or research or anything else) provided that the following conditions are met.

(a) the life of the animal is on balance a life worth live,

(b) the animal otherwise would have no life at all (would not exist), and

(c) the animal will be replaced, at or after death, by another animal in the case of which conditions (a) and (b) hold.

(It is to be understood, of course, that if there are differences of degree among lives which are on balance worth living, then the life of the life of the replacement animal is to be of a least as high a degree as that of the animal it replaces.)

2. By "individuality" I do not mean anything having to do with the quality, nature, or complexity of different personalities or characters. I mean simply the "thisness," as Duns Scotus called it, which quantitatively separates us as different beings.

3. Immanuel Kant, Foundations of the Metaphysics of Morals, trans. Lewis White Beck (Indianapolis: The Library of Liberal Arts, 1959), pp. 46-47

4. Tom Regan, "An Examination and Defense of One Argument Concerning Animal Rights," Inquiry 22/1\&2 (1979), pp. 208-209. T. L. S. Sprigge also uses this argument to advocate animal rights in his essay "Metaphysics, Physicalism, and Animal Rights," Inquiry 22/1\&2 (1979), pp. $101-143$.

5 Regan's "illumination" of why it is wrong to treat independent valuers merely as means is vitiated by his uncritically lumping acknowledging and respecting that independence--a surprising lapse from a philosopher who is usually meticulous in drawing and observing distinctions. If I guard, chain, or cage slaves or animals to keep them from escaping my control, I thereby acknowledge that they place a different value on their lives and conditions than I do. I even "respect" their values in the pragmatic way one "respects" the power of and danger posed by an adversary, although 1 do not "respect" their evaluations of their lives and conditions in the moral 
sense of the term; that is, I do not honor those evaluations, treat them as a basis for rights, consider them to constitute justified claims to something and against me, or feel duty bound not to interfere with responsible attempts to fulfill those values. Such lack of moral respect does not commit the faux pas of denying what these individuals in fact are, i.e., independent valuers; it merely indicates that I am willing to deny these individuals the satisfaction of their desires, needs, wants, etc., in order to satisfy my own. So, Regan's analysis does not show why this attitude towards others is morally objectionable.

- Peter Singer, Practical Ethics (Cambridge: Cambridge University Press, 1979), Chapters 4 and 5.

7 David Hume, A Treatise of Human Nature, Part III, Section xvi, and Richard A. Watson, "Consciousness and the Rights of Nonhuman Animals and Nature," Environmental Ethics 1/2 (1979).

8 S. F. Sapontzis, "Are Animals Moral Beings?," American Philosophical Quarterly 17/1 (1980).

9 Philosophy \& Public Affairs 10/1 (1981), p. 57.

\section{Practical Ethics, p. 81.}

11 Of course, one may desire something yet prefer that it not happen, as when one's desires conflict with his moral commitments. However, failing such conflicts, to desire $X$ is to prefer that it occur. We would suspect that some stipulative definition is at work, if we heard someone say something like "I desire $X$ and feel no conflicting desires or values, yet $I$ do not prefer that $X$ occur."

12 In Interests and Rights (Oxford,
Clarendon Press, 1980), R. G. Frey contends that desiring requires linguistic ability, for (i) desiring $X$ requires believing that we do not currently have $X$ and that having $X$ would improve our condtion and (ii) believing requires linguistic ability because

[in] expressions of the form "He believes that. . .," what follows the "that" is a sentence and what the "he" in question believes is that that sentence and is true (87)

sentences are the sorts of things which $I$ and others regard as capable of being true and false (89).

However, that sentences and beliefs are both capable of being true or false no more establishes a dependence of the latter on the former than the fact that automobiles and evening gowns can both be red establishes that the latter require the former. Similarly, that the object of a belief statement is a sentence no more establishes that the object of a belief is a sentence than the fact that the object of vision is expressed by a word in "I saw John" establishes that the object of perception is a word. When I am thirsty, the object of my desire and of my beliefs about what I lack and what would improve my condition is something to drink, not a sentence about something to drink. No amount of grammatical analysis will change that. And an analysis of how we talk about interests, desires, and beliefs is no substitute for an analysis of interests, desires, and beliefs themselves, which is why Frey's book fails to show that animals lack interests, desires, or beliefs because of their lack of linguistic ability.

13 Jean-Paul Sartre, The Transcendence of the Ego (New York: The Noonday Press, 1957), and Maurice Merleau-Ponty, Phenomenology of Perception (New York: Humanities Press, 1962). 
14 In "Singer on Killing and the Preference for Life" (Inquiry 22/1\&2 (1979), pp. 157-170), Michael Lockwood also questions whether preference utilitarianism draws a significant distinction between humans and animals in regard to the morality of killing and replacing them.

15 Something like Bentham's categories for measuring pleasures, e.g., intensity, duration, and extent, would have to be devised for measuring preferences, since not all preferences are equally preferred.

16 Practical Ethics, pp. 86-87.

17 lbid., p. 87.

18 lbid., pp. 87-88.

19 If the child is not allowed to develop to the point where it will experience pain or other miseries, then there is no harm. However, it is even harder to conceive of people who are so desperate to conceive a child that they would do so knowing full well that the fetus will be aborted before the end of the first trimester.
The only faintly realistic possiblity of this I can image is where the aborted fetus would be crucial for research - toward curing the debilitating disease or birth defect. However, in that case, far from doing wrong, the couple could be considered self-sacrificing, even heroic.

20 Practical Ethics, p. 87.

21 This is not to say that not considering or considering not having normal children is ordinarily an expression of bad moral character--although, contrary to Singer's intuitions, that would be a fairly traditional evaluation.

22 The seventy-five year figure is close to correct if we use average human life expectancy as our basis; the one hundred year figure is correct if we use the normal maximum human life expectancy as our basis, since every human generation seems to produce some centenarians. What the correct figures would be if we included animals, as we should, in figuring the average or normal maximum life expectancy, I do not know. 